Review

\title{
Functional Metabolomics-A Useful Tool to Characterize Stress-Induced Metabolome Alterations Opening New Avenues towards Tailoring Food Crop Quality
}

\author{
Corinna Dawid * (D) and Karina Hille \\ Chair of Food Chemistry and Molecular Sensory Science, Technical University of Munich, \\ Lise-Meitner-Strasse 34, 85354 Freising, Germany; karina.hille@tum.de \\ * Correspondence: corinna.dawid@tum.de; Tel.: +49-8161-71-2923
}

Received: 2 July 2018; Accepted: 2 August 2018; Published: 3 August 2018

\begin{abstract}
The breeding of stress-tolerant cultivated plants that would allow for a reduction in harvest losses and undesirable decrease in quality attributes requires a new quality of knowledge on molecular markers associated with relevant agronomic traits, on quantitative metabolic responses of plants to stress challenges, and on the mechanisms controlling the biosynthesis of these molecules. By combining metabolomics with genomics, transcriptomics and proteomics datasets a more comprehensive knowledge of the composition of crop plants used for food or animal feed is possible. In order to optimize crop trait developments, to enhance crop yields and quality, as well as to guarantee nutritional and health factors that provide the possibility to create functional food or feedstuffs, knowledge about the plants' metabolome is crucial. Next to classical metabolomics studies, this review focuses on several metabolomics-based working techniques, such as sensomics, lipidomics, hormonomics and phytometabolomics, which were used to characterize metabolome alterations during abiotic and biotic stress in order to find resistant food crops with a preferred quality or at least to produce functional food crops.
\end{abstract}

Keywords: plant stress; abiotic stress; biotic stress; metabolomics; phytometabolomics; sensomics; phytohormonics; liquid chromatography-mass spectrometry (LC-MS/MS); nuclear magnetic resonance spectroscopy (NMR); targeted metabolomics; untargeted metabolomics; functional food

\section{Importance of Metabolomics for Agricultural Research}

In the environment, plants are often exposed to an enormous number of biotic and abiotic stress factors, such as pathogen and insect infestation as well as extreme temperatures, drought, salinity, pollutants, heavy metals or nutritional deficiencies. That leads to harvest or quality losses, such as the formation of a pronounced bitter off-flavor and sometimes causes toxicological problems as well as huge global economic losses [1]. The breeding of stress-tolerant cultivated plants that would allow for a reduction in harvest losses and undesirable decrease in quality attributes requires a new quality of knowledge on molecular markers associated with relevant agronomic traits, on quantitative metabolic responses of plants on stress challenges, and on the mechanisms controlling the biosynthesis of these molecules [2]. Thereby, knowledge of the biologically active metabolites, especially secondary metabolites as well as metabolic networks of primary and secondary metabolites affected by plant stress conditions, is essential.

The metabolome of plants represents the complete set of low-molecular weight metabolites (such as primary metabolites including all necessary metabolic intermediates, hormones and other signaling molecules, as well as secondary metabolites) in a given organism, a biological cell, tissue, 
or organ at a certain point in time and development. For a long time, primary and also secondary metabolites were simply considered as one of the end-products of gene expression and protein activity. Nowadays, it is increasingly accepted that low-molecular weight molecules modulate macromolecular processes through, e.g., feedback inhibition and by signaling phytohormons [3]. Therefore, Dixon et al. [3] conclude that, metabolomic studies are "intended to provide an integrated view of the functional status of an organism". But monitoring the whole metabolome with exclusively one technique is not possible at the moment [4]. Although for a single plant like Arabidosis thaliana no more than 5000 metabolites have been assumed, the plant kingdom is reported to contain between 200,000 and 1,000,000 metabolites, all of them having different structural features and polarities [5-9]. This wide structural diversity with different chemical properties is a challenging task during sample extraction and analysis [4]. In addition, the knowledge about functional, secondary metabolites, on having an antifungal, toxic, off-flavor activity or promising human health-promoting activities, is not yet sufficient.

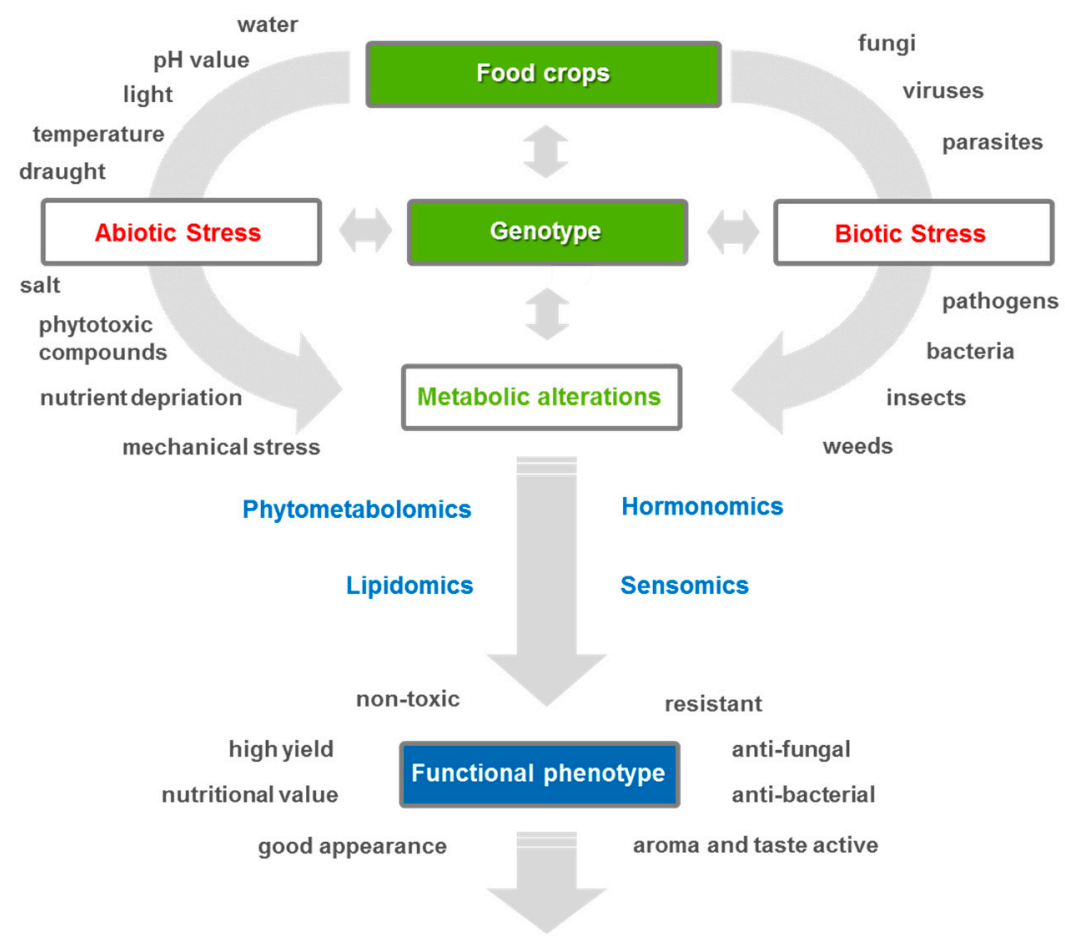

Functional food

Figure 1. Functional metabolomics - a useful tool to discover metabolome alterations during abiotic and biotic stress to find the perfect functional pheno-/genotype to produce functional food.

Therefore, an important aspect of the use of crop plants for human consumption is the characterization and determination of their nutritional value as well as their individual flavor-active, health-promoting, non-toxic, functional constituents. The aim of crop plant research should be to find an optimal functional pheno-/genotype as a golden standard with high resistance and best possible quality criteria for future breeding experiments (cf. Figure 1). Analytical marker compounds can help to support molecular breeding efforts to obtain phenotype knowledge-based plant populations, no matter which analysis method is used, bulk segregant analysis, mapping by sequencing or quantitative trait loci (QTL) analysis $[10,11]$. In sum, metabolomics, especially the characterization of functional relevant metabolites, also called functional metabolomics, can be used as a tool for functional genomics $[2,9,12,13]$. For example, integration of metabolomic data with genomics and transcriptomics, especially that obtained from transcriptome coexpression network analysis, helped to decode several functions of genes and to gain a deep insight into the biological processes of the model 
plant Arabaidopsis [2,9]. Although more studies are desirable, at the moment only manuscripts are available in which secondary, functional metabolites of non-model plants are characterized $[2,9,12,13]$. Next to studies using potatoes, strawberries, carrots or Brassica napus [9,14-18], Rambla et al. [18] performed a QTL analysis using a cross between Solanum lycopersicum and a red-fruited wild tomato species Solanum pimpinellifolium to relate 102 QTLs to 39 corresponding volatile organic compounds, which partly contribute to the typical flavor impression of tomatoes. In addition, by means of genome-wide association studies 323 associations among 143 single nucleotide polymorphisms and 89 metabolites were identified, including non-volatile, functional, secondary metabolites, which can be used for new human drug production [19].

Next to the genetic code, environmental stress especially influences the metabolome composition of plants. Stress conditions are sensed by the plant, which then activates a network of signaling pathways, including the participation of phytohormons, and leads to changes, on the one hand, in the primary metabolism and, on the other hand, in the up-regulation of phytochemicals [20].

For example, during fungi infestations, antifungal phytochemicals, especially metabolic pathways leading to isoprenoids, phenylpropanoids, alkaloids, fatty acids, and polyketides are up-regulated [21]. Many phytoalexins, which partly have been described as flavor-active, nutritional components and as a source for development of health-promoting food products, have been well documented in crop plants in the field of plant defense [21]. In contrast, primary metabolism is documented to be mainly influenced by abiotic stress challenges [5,20-22]. For instance, in Arabidopsis leaves, next to the amino acid profiles, oligosaccharides, $\gamma$-amino butyrate and the metabolites from the tricarboxylic acid cycle are influenced during drought conditions [23].

Analysis of those changes in the molecular composition of plant material by means of mass spectrometry (MS) or nuclear magnetic resonance spectroscopy (NMR) based techniques is called metabolomics, which can profile the impact of time, stress, nutritional status and environmental perturbation on hundreds of metabolites simultaneously. It is an essential technology for functional genomics and systems biology which can visualize and answer questions about biological systems [3,24]. Kushalappa and Gunnaiah [25] already predicted that while in the past, genetic tools were mainly used for crop improvement on yield, flagged as the green revolution, in the next few decades functional genomics, which allows the identification of genes that enhance crop yields without losses in nutritional value while minimizing loss due to stress, will be the main topic. Metabolomics is especially helpful to discover metabolites up-regulated during stress conditions [2]. These metabolites then can be tested for their biological functions. Thereby, the combination and understanding of information received from genomics, transcriptomics, proteomics and metabolomics studies is a complementary tool for functional genomics and systems biology investigations. Although nowadays, next to the human genome [26], the genomes of several plants such as Arabidopsis thaliana [27], rice [28,29], tomato [30], and barley [31] have been decoded by means of automated nucleotide sequencing, knowledge about the regulation of gene expression, about the action of these genetic products, and especially about the metabolic networks resulting from catalytic proteins, is rather fragmentary [3].

Besides aiming to avoid quality or yield losses induced by abiotic or biotic stress conditions, there are exciting new strategies of using plant stress as a way of producing phytoalexin-enriched functional foods [32] or to enhance the flavor quality of crop plants by stress or elicitor challenges to produce new functional foodstuffs with high quality [33]. Dixon et al. [3] additionally suggest that the long-term goal should be the application of new knowledge of functional metabolites for "rational custom-designed breeding by classical methods as well the application of genetic engineering techniques to improve and develop new aromatic plants". Therefore, publicly open databases, containing all spectroscopic, spectrometric and bioactivity data as well as the biosynthetic pathways of worthy metabolites are necessary in the future [3].

Targeted as well as non-targeted metabolomic-based working techniques, such as phytometabolomics, sensomics, lipidomics or hormonomics can help to unravel metabolic pathways, 
signal transmissions as well as metabolites with different bioactivity which can be simultaneously up- or down-regulated by stress conditions. After decoding marker compounds by means of these non-targeted approaches, marker metabolites can be isolated from the plant material and characterized by means of 1/2D-NMR or MS based structure identification techniques as well as by biological assays (e.g., using antifungal susceptibility test systems). Although the last-named structure identification techniques and the testing of the metabolite's bioactivity do not belong to the metabolomics approach, its application is mandatory to understand biological processes.

\section{Analytical Techniques Used to Characterize Stress-Induced Metabolome Alterations in Plants}

Enormous technological progress has been achieved since the early days of plant metabolome characterization. Thin-layer chromatography (TLC) together with gas chromatography coupled to a flame ionization detector (GC-FID) have so far been applied to characterize primary and secondary metabolites in plant materials. Nowadays, besides NMR, high-throughput, sensitive techniques using gas chromatography, liquid chromatography, ultra-high performance liquid chromatography/time-of-flight as well as capillary electrophoresis coupled to mass spectrometry (GC-MS, LC-MS/MS, UHPLC-TOF-MS or CE-MS), together with bioinformatics tools, are state-of the art working techniques $[3,13]$. With the development of mass spectrometry imaging approaches, including matrix-assisted laser desorption (MALDI) or desorption electrospray (DESI) ionization procedures coupled to high resolution mass spectrometers, it is possible to perform metabolomics analysis in situ, as well [34]. Although NMR-based techniques are used in plant metabolomics, it is less common in plant-stress metabolomics. However, new working techniques including NMR-technology, such as differential off-line LC-NMR (DOLC-NMR), show promise for characterizing metabolites upor down-regulated during biotic or abiotic stress influences on plants [35].

Although the term plant metabolomics is defined as the identification and quantification of all low-molecular weight substances in an organism, at a defined point of harvest time and development stage and in a given organ, tissue or cell type, there is no single work-up protocol or standard technique available to detect all metabolites using only one platform. Therefore, several analytical separation and detection techniques are usually combined to visualize abiotic and biotic stress induced metabolome alterations of different plants induced by abiotic and biotic stress [4].

In the last four decades, different methods have been established for the targeted and non-targeted characterization of plant metabolites (cf. the following reviews: Shualev et al. [20]; Urano et al. [22]; Obata and Fernie, [5]; Arbona et al. [4]; Kumar et al. [2]). Nowadays, we differentiate between the non-targeted, sometimes also called untargeted, and the targeted metabolomics approach. While the non-targeted approach represents a comprehensive analysis of all measurable compounds, including unknown metabolites, targeted metabolomics is the measurement of defined groups of chemically characterized and biochemically annotated substances [36]. For both, targeted and non-targeted analyses GC-MS, UHPLC-TOF-MS, as well as LC-MS/MS are the most common techniques to characterize stress-induced metabolome alterations in plants [5].

In particular, primary metabolites, such as carbohydrates, amino acids or fatty acids and all volatile compounds are mainly characterized by means of targeted GC-MS with or without derivatization [37]. Due to the fact that standard compounds are commercially available and spectrometric data is published in several public libraries, such as NIST (National Institute of Standards and Technology), the identification and exact quantification of primary metabolites by means of GC-MS analysis is straightforward. In contrast, structure identification of secondary metabolites exclusively by means of MS data is rather challenging [4,38]. Metabolomics approaches mainly identify secondary non-volatile compounds by means of non-targeted UHPLC-TOF-MS techniques. In contrast to GC-MS, LC-MS libraries for structure identification are less developed, as instrument-type dependent mass spectra and MS fragmentation patterns, as well as retention time shifts depending on used LC columns complicate the comparison of structure identification results using different instruments [39]. In the 
future, a worldwide concept of raw data processing, extensive mass spectral libraries, and powerful database management systems that can store and provide both raw and meta data is desirable.

At the moment, biological active compounds are unequivocally identified by means of MS and 1/2D NMR experiments after their isolation by means of preparative HPLC techniques. But the MS spectra obtained has mostly not been shared with the metabolomics community due to the absence of a standardized data-handling concept. Once identified, sensitive quantitation methods using stable isotope dilution assays (SIDA) are carried out by means of LC-MS/MS or GC-MS techniques. Therefore, nowadays, determination of the exact concentration of the isotopically labelled internal standards can best be achieved by means of quantitative NMR spectroscopy (q NMR) [40].

Although the aforementioned analytical metabolomics techniques nowadays are reliable and very sensitive, they still have their limitations regarding small sample volumes or low quantities of metabolites (partly in the nanomolar range). This is especially so when metabolomics is used to answer specific questions in the field of functional genomics or systems biology to get a comprehensive understanding of plant growth, development, defense or productivity, and knowledge about metabolic pathways and networks at cellular levels is required [9,12,41-43]. In addition to single cell-cell genomics, transcriptomics or proteomics, several groups developed plant single-cell and single-cell type metabolomics during the last decade [43-46]. While using single-cell metabolomics, the metabolome of one individual cell, such as a single epidermal cell, is analyzed, while in single-cell-type metabolomics the metabolome of a population of cells, such as guard cells or trichomes, is characterized [43]. Whereas in studies using single animal cells, more than 300 compounds could, nowadays, be visualized by means of capillary electrophoresis-electrospray ionization-time-of-flight-mass spectrometry (CE-ESI-TOF-MS) methods. The amounts of metabolites characterized in smaller plant-based single-cells is still much lower [42,43]. To gain a better understanding of biological systems and characterize metabolic pathways in single cells or in situ, special attention should, in the future, be given to the development of more sensitive MS apparatuses. This is especially the case in the development of more sensitive visualizing MS techniques, such as MALDI or DESI imaging experiments, and in the improvement of extraction protocols [13,43]. Newly developed derivatisation strategies are also promising strategies to improve the MS sensitivities in future. Next to limitations in measuring low sample amounts, data interpretation sometimes is challenging.

A major challenge for combining all omics-techniques is the integration of detailed metabolomics data into transcriptomic and proteomic profiling data sets $[3,9,12,13,20]$. Although Arbona et al. [4] only recently reviewed the role of metabolomics as a tool to investigate abiotic plant stress in the context of systems biology, and how metabolomics can be integrated into other omics data sets, there is still a lack of knowledge. Furthermore, Urano et al. [22] summarized arguments that holistic omics analysis and their data interpretation are essential to identify the broad function of metabolite regulatory networks during the responses to plant stress. Therefore, bioinformatics knowledge and tools should be used more often in the future to combine the information from both research fields. Although databases and pathway viewers (e.g., an overview is given by Bino et al. [12] or de Souoza et al. [47]) have been further developed in recent years, inter alia Sumner et al. [13] also emphasized that standardized databases integrating metabolomics with other global-omics data are required.

\section{Phytometabolomics-From Plant Stress to Metabolic Response}

Plants continuously encounter various biotic and abiotic environmental stresses during their growth and development phases. While biotic stress is caused by pathogens, parasites, predators, and other competing organisms, abiotic stress arises from inappropriate levels of physical components in the environment, such as temperature or water extremes [21]. Both stress factors lead likewise to yield and quality losses in plant crops used for human nutrition. The aim is, on the one hand, to avoid those immense quality and yield losses to ensure feeding the world's growing population and on the other hand, to develop new functional foods and to reduce insecticides and pesticides used in 
agriculture. Therefore, knowledge of molecular networks and pathway activation of plants during their stress response is essential.

Only recently Mithöfer and Boland [48] asked the question "Do you speak chemistry?". They highlighted that plants always respond by emitting chemical compounds to signal their environment. Moreover, they pointed out that plants use metabolites as chemical sensing and communication systems. On the one hand, signaling molecules and phytoalexins are formed, on the other hand it is suggested that plants "cry for help" by producing secondary metabolites as indirect defense system. Those cry-for-help compounds, usually belonging to the group of volatile organic compounds, attract predators or herbivores helping the plant to get rid of other stress triggers $[48,49]$. Therefore, it is important to notice that stress-specific as well as common metabolites, so-called generalist and specialist, can either be formed or their amounts up-regulated [5].

The understanding of metabolic stress pathways is just possible if comparative metabolite characterization by means of metabolomics analysis of stressed and non-stressed plants followed by structure identification experiments is performed. In the following three sub-sections an initial overview of the literature about biotic and abiotic stress studies is undertaken.

\subsection{From Abiotic Plant Stress to Metabolic Response}

It is well expected that climatic changes due to the global warming will lead to massive abiotic stress factors influencing the metabolome spectra of all plants in the future. Next to water stress, including soil flooding and drought stress, salt stress, temperature stress, light stress, sulfur and phosphorus stress, oxidative stress, as well as heavy metal stress will play important roles for food crop producers. To understand and avoid quality and yield losses induced by abiotic stress factors, several metabolomics studies have been carried out (cf. the following reviews: Shulaev et al. [20]; Kaplan et al. [21]; Urano et al. [22]; Obata and Fernie [5]; Arbona et al. [4]).

Among them, Arbona et al. [4] already summarized in their review "Metabolomics as a tool to investigate abiotic stress tolerance in plants" that the plants' metabolic responses to abiotic stress can mainly be found in the primary metabolism. Next to metabolic responses in mono- and disaccharides, sugar alcohols, amino acids, especially proline, polyamines and members of the tricarboxylic acid cycle were found to be influenced by abiotic factors. Thereby, the carbohydrate metabolism in particular is directly influenced by stress conditions, because during stress instead of glucose, plants use fructanes and starch as an energy source [50].

In their review, Obata and Fernie [5] compared several metabolic fingerprints of Arabidopsis leaves influenced by dehydration, salt, heat and cold, high light and sulfur limitation, ultraviolet (UV) light quality change, low nitrogen amounts, and potassium limitation with each other. Thereby, they highlighted that specific compounds and compound classes are generally accumulated during abiotic stress factors (except of light treatment), such as sucrose, raffinose, proline, other branched chain amino acids or $\gamma$-aminobutyric acid (GABA). However, the amounts of such up-regulated "generalists" varies between stress factors. They concluded, that the stress-specific plant response is the result of an inhibition or activation of a defined metabolic pathway. In particular, enzymes activities are known to be influenced by temperature or ion concentrations in plants. By contrast, other metabolites are accumulated only under specific conditions, such as trehalose.

Next to the carbohydrates, the lipid composition of plants is additionally influenced by abiotic stress factors. Lipids in plants are a crucial and diverse class of biomolecules that forms the so called plant lipidome. Lipidomics is defined as the identification and quantification of all lipids within a biological system at a defined stage of development [51]. Within the field of omics-analysis lipidomics represents a sub-unit of targeted and non-targeted metabolomics approaches, mainly using MS- and NMR-based techniques. The development of lipidomics and its increased promise in systems biology over the past two decades has been the subject of several reviews (e.g., Blanksby and Mitchell [34]). Changes in the lipidome, induced by modifications of its biosynthesis, regulation, adaption, remodeling, function, role, and interaction, as well as membrane lipid remodeling are 
relevant responses from plant cells to counteract biotic and abiotic stress challenges [51]. In particular, the oxidation of polyunsaturated fatty acids is one of the most fundamental reactions in lipid chemistry, which for example leads to off-flavor (perceived rancidity) or to phytohormon precursor formations [52]. Different groups of lipids, such as fatty acids, phosphatidic acids, inositol phosphates, diacylglycerols, oxylipins, shingolipids, and $\mathrm{N}$-acetylethanolamine are involved in signaling systems during stress conditions as well [53-58]. Those compounds are shown to be directly synthesized after abiotic stress influences by a wide range of enzymes, such as fatty acid amide hydrolases, phospholipases, acyl hydrolases, diacylglycero kinases or phytoshingosine kinases [58]. In addition, it is known that in response to abiotic stress factors, lipids migrate into cell walls to repair damage through membrane remodeling [58-60]. Moreover, a combination of transcriptomics and lipidomic profiling showed that cold stress induces the prokaryotic pathway and suppresses the eukaryotic pathway for glycerolipid biosynthesis [61]. Next to cold stress, light and temperature stress, as well as nutrient starvation as typical abiotic stress factors were studied by means of lipidomic approaches in Arabidopsis (for details cf. the following review: Tenenboim et al. [51]). Only recently, lipidomics studies led to the clarification of the role of leaf lipids in thyme plant response to drought stress [58].

In the future, more stress-related lipidomic studies are expected, due to the fact that in nutritional research lipid profiling also plays a crucial role [51]. The food industry, for example, shows great interest in the use of lipidomics to characterize defined crop plant genotypes. As a replacement of palm kernel fat by a natural alternative, new plant genotypes having the same triglyceride pattern are needed. Furthermore, although most genes annotated as lipid-related are functionally characterized, their corresponding metabolites are not assigned. That would be an interesting field of research in the future, as well.

Next to numerous papers and reviews which highlight metabolome alterations induced by one single stress factor, Karin Köhl's review [62] gives a very nice overview of the metabolites influenced by combined abiotic stress effects in crops. Due to the fact that plants often have to deal with more than one stress factor, further metabolomics studies in crops which take several stress factors into account would be useful in the future [62].

In sum, although integrated omics data of model plants such as Arabidopsis have markedly increased our knowledge of understanding the mechanisms involved in plants' response to various abiotic stress factors $[22,63,64]$, knowledge about secondary metabolome alterations in abiotic stressed food crops is rather fragmentary. Only few studies indicate abiotic stress influences the amounts of phenolic compounds, glucosinolates, carotinoides terpene derivatives and phytohormons in plants [4,51]. Urano et al. [22] emphasize again and again that phytohormon levels, especially those of abscisic acid, vary a lot in different plant compartments. Next to knowledge gaps in the stress influence on the secondary metabolome, more studies are needed to characterize stress combinations as well [5].

\subsection{From Biotic Stress Metabolomics to Metabolic Response}

During biotic stress exposure, plants use qualitative and quantitative measures to resist pathogen attacks [65]. While, in the past, the qualitative resistance, based on monogenetic inheritance, has been successfully used to elite cultivars to improve resistance, the quantitative resistance, which is presumed to be durable, non-race-specific, and effective against a large bouquet of pathogens, is mainly unknown [25]. However, a huge number of quantitative trait loci (QTLs) associated with qualitative resistance against pathogen-associated molecular patterns (PAMs), found for example in soy beans (Glycine max), and with quantitative resistance, found for blast in barley (Hordeum vulgare), or powdery mildew in wheat, have already been identified for biotic stress challenges [25,66-70]. However, both the mechanisms of resistance and the metabolites up-regulated during plant stress controlled by the QTLs are mainly unexplored [66]. In particular, targeted metabolomics approaches enable the possibility to monitor marker compounds up-regulated during plant stress. They can then be isolated, identified and biologically characterized, for example by application of an antifungal test. 
Non-targeted metabolomics in comparison with bioinformatics and database research can also give an idea of which metabolic pathways are activated during a plant's stress response. Moreover, targeted analysis of known bioactive, e.g., anti-microbial or anti-fungal, compounds can help to identify QTLs, by using targeted metabolomics techniques for phenotyping experiments in breeding crossing lines. Thereby, alongside breeding improvement, metabolomics helps in the understanding of biological functions and the study of host-pathogen interactions [25].

It is already known from plant-pathogen interaction studies that signaling molecules, such as ethylene, salicilic acid, jasmonic acid or inositol, as well as antifungal/antimicrobial phytochemicals and cell wall compartments are formed or their concentrations up-regulated during plant stress [25]. Numerous studies already indicate that a complex network of secondary metabolites is influenced by biotic stress challenges. Next to phenylpropanoids, including flavonoids [34,50,51,71], alkaloids [72,73], terpenoids [33], and fatty acids [74] are also known to be up-regulated [25]. In addition, lipids act under pathogen or herbivore attack as mechanical barriers. The plants' wax layers form the first line of defense against pathogens and herbivores [51,75]. Additionally, some lipids act as signaling molecules, namely oxylipins and jasmonates, which participate in immune response cascades. Phytoalexins, a group of fatty acid degradation products, have antimicrobial and antifungal activities [51]. In addition, only recently Caroline Gutjahr's lab could show that fatty acids, like carbohydrates, are also transported from the plant host to fungi [76].

Moreover, as plants produce a diverse array of more than 100,000 low molecular weight natural products [32], countless studies are available using targeted quantifications of phytoalaxins in plants.

In 2009, Boue et al. [32] published a forward-looking paper called "phytoalexin-enriched functional foods" in which they proposed to use stress conditions to enhance the amounts of phytoalexins in food plants to produce functional foods. Several phytoalaxins are known for their health beneficial properties, including antioxidant activities, anti-inflammatory activities, cholesterol-lowering abilities, and anticancer activities [32]. In particular, flavonoids, which are ubiquitous in many food plants, have been linked to important health-promoting activities. For example, consumption of legumes, especially soy, have been linked to the reduction of cancer risks and coronary heart diseases simply due to its high flavonoid content [32]. Therefore, besides resistance and yield stability, functional food ingredients from the phytoalexin family could also be a possible target for plant breeders. In addition, mild stress conditions could possibly help to enhance the amounts of bioactive secondary metabolites, thereby producing functional foods [32].

Next to aspects in nutrition, diet and health, food and environmental safety can especially be monitored by means of metabolomics [3]. Toxic compounds can, for example, be formed as a stress response by plants, such as furanocoumarins in celery and glycoalcaloides in potatoes, or by fungi contamination, which can produce human toxic mycotoxins [77]. Therefore, versatile, sensitive, reliable and fast-targeted LC-MS/MS and GC-MS methods using stable isotope dilution techniques have been developed in the past to monitor food quality [78,79].

In sum, in the future more versatile and sensitive multiple-targeted MS quantification methods to evaluate food and crop quality are required.

\subsection{Functional Phytometabolomics—Characterization Approach of Plant Stress Metabolites}

In conclusion, the science-driven breeding of stress-tolerant cultivated plants that would allow for a reduction in harvest losses and undesirable decrease in quality attributes requires a new quality of knowledge on molecular markers associated with relevant agronomic traits, on quantitative metabolic stress responses of plants, and the mechanisms controlling their biosynthesis. The field of "functional phytometabolomics", using targeted and non-targeted MS or NMR techniques to quantitatively assess key metabolome alterations in plant-derived crops and foods induced by biotic stress challenges as well as abiotic stress conditions, is, therefore, a promising field of research.

In the phytometabolomics approach, metabolites up-regulated during stress challenges are visualized by means of working techniques used in the field of metabolomics. Markers previously 
not published in literature could e.g., be visualized by retention time and mass to charge ratio in UHPLC-TOF-MS analysis. They are isolated in purities higher than $98 \%$ from the plant material using medium pressure liquid chromatography (MPLC) and preparative HPLC techniques and are identified by means of LC-MS, LC-MS/MS, UHPLC-TOF-MS and 1/2D NMR experiments. Testing of different biological activities (anti-fungal, anti-bacterial, anti-oxidant activities etc.) of those compounds allows initial insights into their biological functions. To translate the knowledge on how stress-resistant traits master their successful defense against stress conditions into breeding programs, genotype-specific metabolome alterations have to be characterized. Subsequently, the gene clusters controlling the biosynthetic pathways of key stress metabolites have to be identified by means of genome-wide association and QTL mapping studies. Just to highlight two examples: Firstly, Matsuda et al. [19] characterized several bioactive flavon glycosides, which can be used for new human drug discovery in rice by means of a metabolom genome-wide association study. Thereby, they highlighted "that one plant species produces more diverse phytochemicals than previously expected, and plants still contain many useful compounds for human applications". Secondly, only recently Rambla et al. [18] used a QTL analysis, to show that 102 QTLs correspond to 39 different volatile organic compounds, including flavor active key metabolites, in tomatoes. This research will help to navigate breeding programs and to optimize post-harvest treatment of plant-derived food products from producer to consumer/processor towards the production of high-quality food products.

\section{Phytohormone Profiling by Means of Plant Hormonomics}

Phytohormones are a class of low molecular weight, structurally diverse, but highly bioactive compounds in plants. They act as chemical messengers, triggering and controlling physiological processes during plant growth and development (e.g., cell elongation, regulation of apical dominance, vascular differentiation, fruit development, latal and adventitious root formation) as well as in response to abiotic and biotic stress conditions $[2,80,81]$. Next to ethylene, auxins, cytokinins, brassinosteroids, gibberellins, jasmonates, salicylates, polyamines, abscisates and signal peptides, strigolactones are part of the phytohormone family $[81,82]$. During stress exposure those phytohormone classes interact with each other by means of synergistic or antagonistic cross-talks, resulting in each other's biosynthesis or up-regulation response [83]). In the past, several studies provided evidence that plant hormones are necessary for plants to adapt during stress conditions, especially, during abiotic stress factors by mediating a wide range of adaptive responses [83]. They play a key role in the plant's intricate signal networks, often immediately altering gene expression by inducing or preventing the degradation of transcriptional regulators via the ubiquitin-proteasome system [83,84]. Thanks to Kumar et al. [2], metabolic engineering of phytohormons can be used to improve quality and stress tolerance of crops. Although the analysis of plant hormones, such as auxins, especially their quantification by means of SIDA-LC-MS/MS revealed significant insights in their tissue- and cell-type-specific analysis, their distribution profiles in plant organs, tissues, and cells still remains elusive [81]. A wide variety of targeted GC-MS and LC-MS/MS methods have been published dealing with the quantification of exact amounts of single members of the phytohormone family (e.g., cf.: Porifiro et al. [85]; Novák et al. [81]). However, in the last two decades, only one method was described to characterize those physiologically important molecules in their network interactions in one single run [86]. Only recently, Ondřej Novák and his team developed a new, versatile and sensitive targeted UHPLC-MS/MS method, which enables the simultaneous quantification of 101 phytohormone-related metabolites (phytohormones and their precursors) in less than $20 \mathrm{mg}$ plant material [86]. This allows the characterization of the majority of known phytohormones as well as their biosynthetic precursors, that regulate diverse processes in plants by intricate signaling networks. With this newly developed, targeted metabolomics approach, so called "plant hormonomics", Šimura et al. [86] were able to detect 45 and quantify a total of 43 endogenous compounds out of the 101 phytohormones in both root and shoot samples, in salt-stressed and non-stressed, 12-day-old Arabidopsis thaliana seedlings. Subsequent multivariate statistical analysis cross-compared with data obtained from transcriptomic studies enabled the identification of the 
main phytohormones involved in the adaption of Arabidopsis thaliana to salt stress. The multivariate statistical analysis revealed that 23 of the quantified 43 metabolites significantly differed between the salt-stressed and non-stressed roots. In contrast, the shoots and the roots differed in the concentrations of 15 compounds. Those hormone profiles obtained were cross-compared with transciptomic data. Well in line with findings from Rhy and Cho [87], who found that jasmoic acid and abscisic acid promote salt tolerance in Arabidopsis, Šimura et al. [86] observed increased levels of abscisic acid, its oxidation products phaseic acid, dihydrophaseic acid, and jasmonic acid in salt-stressed root samples. In addition, different responses of gibberillinic acid derivatives, especially its active form GA4, and its transcriptomic data, were found by Šimura et al. [86]. In sum, this newly developed multiple parallel analysis of phytohormones, called "plant hormonomics" enables the real-time profiling of hormone networks of large collections of phytohormones, their precursors, transport forms and degradation products in single stressed or non-stressed samples [86,88].

Although, Šimura et al. [86] were already able to quantify the main phytohormones in less than $20 \mathrm{mg}$ of salt stressed Arabidopsis samples, special derivatisation reactions of the analytes prior to their analysis will conceivably lead to an increase in sensitivity and selectivity during MS analysis in the future [85,88-90]. For example, the response/sensitivity during LC-ESI-MS/MS analysis of metabolites only present in very low concentrations in plants, like indole-3-acetic acid, a member of the auxin family, can be tremendously increased up to 200-fold after methylation [89]. In addition, several aldehyde trapping derivatisation reagents are known to enhance the sensitivity during ESI-MS analysis of biological mixtures [91]. In future, it could be an extremely important and advantageous step in hormonomics to analyze a combination of derivatised and non-derivatised phytohormone classes, simultaneously in one method.

\section{Sensomics-A Phenotyping Tool to Characterize Crops Flavor Impression}

In general, more than $83 \%$ of consumers say that flavor influences their decision the most when purchasing any kind of food products or beverages [92]. Therefore, it is no surprise that, although aided by visual inspection, the final recognition and quality evaluation of food crops made by consumers are mainly mediated by its flavor perception. Human flavor perception is induced by the interaction of volatile odor-active and non-volatile taste-active molecules with $\sim 390$ odorant receptor proteins located in the regio olfactoria in the nose and $\sim 40$ taste receptor proteins on the tongue [93]. To meet consumers' demand for continuously available, fresh foods with a premium quality, the "flavor blueprint" of a golden standard, which is a combinatorial code of the entire set of odor- and taste-active metabolites in their natural concentrations, has to be known [94]. To decode all flavor-active molecules of a crop, the so-called sensometabolome, several high-end working techniques, including combinations of state-of-the-art metabolomics and chromatography approaches in combination with human sensory science experiments, such as aroma or taste dilution analysis, have been developed in the past. This so called molecular sensory science or sensomics approach has especially been shaped by Peter Schieberle's and Thomas Hofmann's working groups during the last three decades $[93,94]$. Today, it is well accepted that the presence of certain structural elements, so-called olfactophores and gustophores, as well as specific concentrations exceeding the sensory thresholds are important prerequisites of low molecular weight metabolites to become flavor-active [94]. Although a total of more than 10,000 volatiles occur in crop plants, the use of the so-called sensomics approach gave evidence that the typical aroma impression of a crop-based foodstuff is caused by a limited number of aroma-active volatiles [93]. In conclusion, only a surprisingly small group of so called "key odorants in food" contribute to the typical aroma profile of a crop plant. For example, only two compounds, namely ethyl (2S)-2-methylbutanoate and 1-(ethylsulfanyl)ethane-1-thiol, are necessary to explain the typical aroma impression of durian fruits [95], and to mimic the typical aroma impression of mangos only eight compounds are required [96]. While only a small number of aroma-active compounds contribute to the key odorants in food and interact with a huge number of odorant receptors, several thousands of non-volatile taste-active compounds are already known. In particular, the application of taste dilution 
analysis followed by dose/activity considerations led to the discovery of many bitter, sweet, umami, pungent, astringent, salty, or sour sensing molecules in several plants, such as carrots [97,98], cocoa [99], asparagus [100-102], pepper [103], red currants [104], tea [105], stevia [106] or spinach [107] in the past. It is nowadays well accepted that not only a single flavor-impact molecule, but a combinatorial code of multiple odor- and taste-active key compounds, each in its specific concentration, reflect the chemosensory phenotype and trigger the typical flavor profile of food products. In particular, for flavor improvement of crops, the analysis of aroma- and taste-active compounds presents a major challenge for flavor improvement of crops [94]. It has been shown in the past, that the biosynthesis of several key odorants in food and tastants is controlled by genes, the expression of which is altered or even induced by biotic or abiotic stress challenges. But the primary target of crop production then was field performance, yield, and storage characteristics, while ignoring quality traits, such as the flavor code $[33,108]$.

On the one hand, induced by several biotic and abiotic stress factors during growth in the field as well as during post-harvest storage, the attractive sensory quality of miscellaneous crop plants is hindered by sporadic off-flavors, which is often the reason for consumer complaints and therefore a major problem for plant processors. On the other hand, mild stress factors can lead to an increase in in the concentration of flavor-active constituents and hence to a more intensive desirable aroma or taste impressions $[33,108]$.

Moreover, abiotic factors, such as mechanical stress, are reported to increase the amounts of the key bitter tastants, members of the C17-polycetylenes, present in native carrots (Daucus carota L.). The increase causes a perceived bitter off-flavor, occurring especially often during the production process for infant diet carrot products $[97,98,109-115]$. In addition, a decrease in flavor quality accompanied by an increase in bitter taste has also been reported in raw hazelnuts (Corylus avellana L.) upon biotic stress challenges, such as upon infection by bugs, belonging to the hemipteran family, like Gonocerus acuteangulatus and Coreus marginatus [116].

Besides the non-volatile, taste-active metabolites, aroma-active compounds are also known to be influenced by individual stress factors [33]. In particular, studies dealing with tea (Camellia sinensis), which is enjoyed as freshly brewed green, black, oolong, or decaffeinated tea infusion, and its quality changes induced by stress are available in literature. For example, the tea green leafhopper (Empoasca (Matsumurasca) onukii Matsuda) attacks, at pre-harvest stages, can decisively influence the unique aroma quality of tea leaves as a result of the upregulation of the linalool synthase (CsLIS1 and CsLIS2) causing higher concentrations of the key odorant, linalool $[33,117]$. Besides linalool, the formation of key odorants, such as $(E)$-nerolidol, can also be influenced by a combination of low-temperature stress and mechanical damage [33,118]. Therefore, Wüst [33] concluded that the tea-related findings illustrate how the use of the stress response of plants within the sensometabolome can lead to an improvement of flavor of agricultural products. In addition, he pointed out, that the plants' contact with stress elicitors, such as methyl jasmonate instead of the actual biotic or abiotic stress factors could also lead to "stress induced" flavor improvement [33,118].

In order to gain a more comprehensive knowledge on the chemical mechanisms involved in quality changes of cultivated crop plants in response to biotic or abiotic stress challenges or to improve the flavor quality by the application of moderate, well controlled stress, numerous volatile, aroma-active as well as non-volatile taste-active key metabolites, the so-called sensometabolites, of stressed and non-stressed plant genotypes should be comparatively characterized by means of a fast and robust high-throughput GC-MS systems with high peak separation capacity and sensitivity, such as comprehensive two-dimensional gas chromatography/time-of-flight mass spectrometry $(\mathrm{GC} \times \mathrm{GC} / \mathrm{TOF}-\mathrm{MS})$ or UPLC-TOF-MS metabolic profiling analysis in the future. This strategy aims at reducing the flavor deficiencies in modern commercial varieties as a "green" alternative to genetic engineering. The workflow for a successful implementation of this approach-from the identification of key odorants by molecular science techniques to the investigation of mechanisms controlling their biosynthesis-is complex and calls for interdisciplinary research [33,108]. 


\section{Conclusions}

Plants continuously encounter various biotic and abiotic environmental stresses during their growth and development phases, which leads likewise to yield and quality losses. To avoid those previously listed economical losses, to reduce insecticides and pesticides used in agriculture, to ensure feeding the world's growing population, and to develop new functional foods knowledge about molecular networks and the pathway activation of plants during their stress response is essential.

This review has emphasized the importance of metabolomics-based working techniques to discover metabolome alterations during abiotic and biotic stress conditions. Therefore, metabolomics is a promising tool for knowledge-based targeted breeding programs. It also shows that due to missing databases and non-standardized LC-MS conditions, basic metabolomics, lipidomics and phytohormonics strategies, without isolation and unequivocal structure identification experiments, are sometimes insufficient. Therefore, techniques using biological and molecular structural characterizations of marker metabolites in combination with metabolomics techniques, such as phytometabolomics or sensomics approaches, are useful solutions to produce high-quality phytoalexin-enriched functional foods in the future.

Author Contributions: C.D. wrote the manuscript. K.H. critically revised the final version of the manuscript.

Funding: Work in the Dawid lab is funded by the SFB924/TP-B12.

Conflicts of Interest: The authors declare no conflict of interest.

\section{References}

1. Börner, H. Pflanzenkrankheiten und Pflanzenschutz, 8th ed.; Springer-Verlag: Berlin/Heidelberg, Germany, 2009.

2. Kumar, R.; Bohra, A.; Pandey, A.K.; Pandey, M.K.; Kumar, A. Metabolomics for Plant Improvement. Status and Prospects. Front. Plant Sci. 2017, 8, 1302. [CrossRef] [PubMed]

3. Dixon, R.A.; Gang, D.R.; Charlton, A.J.; Fiehn, O.; Kuiper, H.A.; Reynolds, T.L.; Tjeerdema, R.S.; Jeffery, E.H.; German, J.B.; Ridley, W.P.; et al. Application of metabolomics in agriculture. J. Agric. Food Chem. 2006, 54, 8984-8994. [CrossRef] [PubMed]

4. Arbona, V.; Manzi, M.; de Ollas, C.; Gómez-Cadenas, A. Metabolomics as a tool to investigate abiotic stress tolerance in plants. Int. J. Mol. Sci. 2013, 14, 4885-4911. [CrossRef] [PubMed]

5. Obata, T.; Fernie, A. The use of metabolomics to dissect plant responses to abiotic stresses. Cell. Mol. Life Sci. 2012, 69, 3225-3243. [CrossRef] [PubMed]

6. De Luca, V.; St Pierre, B. The cell and developmental biology of alkaloid biosynthesis. Trends Plant Sci. 2000, 5, 168-173. [CrossRef]

7. D'Auria, J.C.; Greshenzon, J. The secondary metabolism of Arabidopsis thalina: Growing like a weed. Curr. Opin. Plant Biol. 2005, 8, 308-316. [CrossRef] [PubMed]

8. Davies, H. A role for "omics" technologies in food safety assessment. Food Control 2010, 21, 1601-1610. [CrossRef]

9. Saito, K.; Matsuda, F. Metabolomics for funtional genomics, systems biology, and biotechnology. Annu. Rev. Plant Biol. 2010, 61, 463-489. [CrossRef] [PubMed]

10. Cantu, D.; Govindarajulu, M.; Kozik, A.; Wang, M.; Chen, X.; Kojima, K.K.; Dubcovsky, J. Next generation sequencing provides rapid access to the genome of Puccinia striiformis $\mathrm{f}$. sp. tritici, the causal agent of wheat stripe rust. PLOS ONE 2011, 6, e24230.

11. Schneeberger, K.; Weigel, D. Fast-forward genetics enabled by new sequencing technologies. Trends Plant Sci. 2011, 16, 282-288. [CrossRef] [PubMed]

12. Bino, R.J.; Hall, R.D.; Fiehn, O.; Kopka, J.; Saito, K.; Draper, J.; Nikolau, B.J.; Mendes, P.; Roessner-Tunali, U.; Beale, M.H.; et al. Potential of metabolomics as a functional genomics tool. Trends Plant Sci. 2004, 9, 1360-1385. [CrossRef] [PubMed]

13. Sumner, L.W.; Lei, Z.; Nikolau, B.J.; Saito, K. Modern plant metabolomics. Advanced natural product gene discoveries, improved technologies, and future prospects. Nat. Prod. Rep. 2015, 32, 212-229. [CrossRef] [PubMed] 
14. Aharoni, A.; Keizer, L.C.; Bouwmeester, H.J.; Sun, Z.; Alvarez-Huerta, M.; Verhoeven, H.A.; Blaas, J.; van Houwelingen, A.M.; De Vos, R.C.; van der Voet, H.; et al. Identification of the SAAT gene involved in strawberry flavor biogenesis by use of DNA microarrays. Plant Cell. 2000, 12, 647-662. [CrossRef] [PubMed]

15. Carreno-Quintero, N.; Acharjee, A.; Maliepaard, C.; Bachem, C.W.B.; Mumm, R.; Bouwmeester, H.; Visser, R.G.F.; Keurentjes, J.J.B. Untargeted metabolic quantitative trait loci analyses reveal a relationship between primary metabolism and potato tuber quality. Plant Physiol. 2012, 158, 1306-1318. [CrossRef] [PubMed]

16. Feng, J.; Long, Y.; Shi, L.; Shi, J.; Barker, G.; Meng, J. Characterization of metabolite quantitative trait loci and metabolic networks that control glucosinolate concentration in the seeds and leaves of Brassica napus. New Phytol. 2012, 193, 96-108. [CrossRef] [PubMed]

17. Keilwagen, J.; Lehnert, H.; Berner, T.; Budahn, H.; Mothnagel, T.; Ulrich, D.; Dunemann, F. The terpene synthase gene family of carrot (Daucus carota L.): Identification of candidate genes associated with terpenoid volatile compounds. Front. Plant Sci. 2017, 8, 1930. [CrossRef] [PubMed]

18. Rambla, J.L.; Medina, A.; Fernández-Del-Carmen, A.; Barrantes, W.; Grandillo, S.; Cammareri, M.; López-Casado, G.; Rodrigo, G.; Alonso, A.; García-Martínez, S.; et al. Identification, introgression, and validation of fruit volatile QTLs from a red-fruited wild tomato species. J. Exp. Bot. 2017, 68, 429-442. [CrossRef] [PubMed]

19. Matsuda, F.; Nakabayashi, R.; Yang, Z.; Okazaki, Y.; Yonemaru, J.; Ebana, K.; Yano, M.; Saito, K. Metabolome-genome-wide association study dissects genetic architecture for generating natural variation in rice secondary metabolism. Plant J. Cell Mol. Boil. 2015, 81, 13-23. [CrossRef] [PubMed]

20. Shulaev, V.; Cortes, D.; Miller, G.; Mittler, R. Metabolomics for plant stress response. Physiol. Plant. 2008, 132, 199-208. [CrossRef] [PubMed]

21. Kaplan, F.; Kopka, J.; Haskell, D.W.; Zhao, W.; Schiller, K.C.; Gatzke, N.; Sung, D.Y.; Guy, C.L. Exploring the temperature-stress metabolom of Arabidopsis. Plant Physiol. 2004, 136, 4159-4168. [CrossRef] [PubMed]

22. Urano, K.; Kurihara, Y.; Seki, M.; Shinozaki, K. 'Omics' analyses of regulatory networks in plant abiotic stress responses. Curr. Opin. Plant Biol. 2010, 13, 132-138. [CrossRef] [PubMed]

23. Urano, K.; Maruyama, K.; Ogata, Y.; Morishita, Y.; Takeda, M.; Sukarai, N.; Suzuki, H.; Saito, K.; Shibata, D.; Kobayashi, M.; et al. Characterization of the ABA-regulated global responses to dehydration in Arabidopsis by metabolomics. Plant J. 2009, 57, 1065-1078. [CrossRef] [PubMed]

24. Ghatak, A.; Chaturvedi, P.; Weckwerth, W. Metabolomics in Plant Stress Physiology. In Advances in Biochemical Engineering/Biotechnology; Springer: Berlin/Heidelberg, Germany, 2018.

25. Kushalappa, A.C.; Gunnaiah, R. Metabolo-proteomics to discover plant biotic stress resistance genes. Trends Plant Sci. 2013, 18, 522-531. [CrossRef] [PubMed]

26. Venter, J.C.; Adams, M.D.; Myers, E.W.; Li, P.W.; Mural, R.J.; Sutton, G.G.; Smith, H.O.; Yandell, M.; Evans, C.A.; Holt, R.A.; et al. The sequence of the human genome. Science 2001, 291, 1304-1351. [CrossRef] [PubMed]

27. The Arabidopsis Genome Initiative. Analysis of the genome sequence of the flowering plant Arabidopsis thaliana. Nature 2000, 408, 796-815. [CrossRef] [PubMed]

28. Goff, S.A.; Ricke, D.; Lan, T.H.; Presting, G.; Wang, R.L.; Dunn, M.; Glazebrook, J.; Sessions, A.; Oeller, P.; Varma, H.; et al. A draft sequence of the rice genome (Oryza sativa L. ssp. japonica). Science 2002, 296, 92-100. [CrossRef] [PubMed]

29. Yu, J.; Hu, S.N.; Wang, J.; Wong, G.K.S.; Li, S.G.; Liu, B.; Deng, Y.J.; Dai, L.; Zhou, Y.; Zhang, X.Q.; et al. A draft sequence of the rice genome (Oryza sativa L. ssp. indica). Science 2002, 296, 79-92. [CrossRef] [PubMed]

30. Sato, S.; Tabata, S.; Hirakawa, H.; Asamizu, E.; Shirasawa, K.; Isobe, S.; Kaneko, T.; Nakamura, Y.; Shibata, D.; Aoki, K.; et al. The tomato genome sequence provides insights into fleshy fruit evolution. Nature 2012, 485, 635-641.

31. Mascher, M.; Gundlach, H.; Himmelbach, A.; Beier, S.; Twardziok, S.O.; Wicker, T.; Radchuk, V.; Dockter, C.; Hedley, P.E.; Russell, J.; et al. A chromosome conformation capture ordered sequence of the barley genome. Nature 2017, 544, 427-433. [CrossRef] [PubMed]

32. Boue, S.M.; Cleveland, T.E.; Carter-Wientjes, C.; Shih, B.Y.; Bhatnagar, D.; McLachlan, J.M.; Burow, M.E. Phytoalexin-enriched functional foods. J. Agric. Food Chem. 2009, 57, 2614-2622. [CrossRef] [PubMed]

33. Wüst, M. Smell of stress: Identification of induced biochemical pathways affecting the volatile composition and flavor quality of crops. J. Agric. Food Chem. 2018, 66, 3616-3618. [CrossRef] [PubMed] 
34. Blanksby, S.J.; Mitchell, T.W. Advances in mass spectrometry for lipidomics. Annu. Rev. Anal. Chem. 2010, 3, 433-465. [CrossRef] [PubMed]

35. Hammerl, R.; Frank, O.; Hofmann, T. Differential off-line LC-NMR (DOLC-NMR) metabolomics to monitor tyrosine-induced metabolome alterations in Saccharomyces cerevisiae. J. Agric. Food Chem. 2017, 65, 3230-3241. [CrossRef] [PubMed]

36. Roberts, L.D.; Souza, A.L.; Gerszten, R.E.; Clish, C.B. Targeted Metabolomics. Curr. Protoc. Mol. Biol. $2012,30$. [CrossRef] [PubMed]

37. Desbrosses, G.; Steinhauser, D.; Kopka, J. Metabolom analysis using GC-MS. In Lotus Japonicus Handbook; Springer: Dordrecht, The Netherlands, 2005; pp. 165-174.

38. Burton, L.; Ivosev, G.; Tate, S.; Impey, G.; Wingate, J.; Bonner, R. Instrumental and experimental effects in LC-MS-based metabolomics. J. Chromatogr. B 2008, 871, 227-235. [CrossRef] [PubMed]

39. Moco, S.; Bino, R.J.; Vorst, O.; Verhoeven, H.A.; de Groot, J.; van Beek, T.A.; Vervoort, J.; de Vos, C.H. A liquid-chromatography-mass spectrometry based metabolome database for tomato. Plant Physiol. 2006, 141, 1205-1218. [CrossRef] [PubMed]

40. Frank, O.; Kreißl, J.K.; Daschner, A.; Hofmann, T. Accurate determination of reference materials and natural isolates by means of quantitative 1H NMR spectroscopy. J. Agric. Food Chem. 2014, 62, 2506-2515. [CrossRef] [PubMed]

41. Sumner, L.W.; Mendes, P.; Dixon, R.A. Plant metabolomics: Large-scale phytochemistry in the functional genomics area. Phytochemistry 2003, 62, 817-836. [CrossRef]

42. Wang, D.; Bodowitz, S. Single cell analysis: The new fronzier in òmics. Trends Biotechnol. 2010, 28, $281-290$. [CrossRef] [PubMed]

43. Misra, B.B.; Assmann, S.M.; Chen, S. Plant single-cell and single-cell-type metabolomics. Trends Plant Sci. 2014, 19, 637-646. [CrossRef] [PubMed]

44. Lange, B.M. Single cell genomics. Curr. Opin. Plant Biol. 2005, 8, 236-241. [CrossRef] [PubMed]

45. Tang, F.; Lao, K.; Surani, M.A. Development and applications of single cell transcriptome analysis. Nat. Methods 2011, 8, 6-11. [CrossRef] [PubMed]

46. Dai, S.; Chen, S. Single cell-type proteomics: Toward a holistic understanding of plant function. Mol. Cell. Proteom. 2012, 11, 1622-1630. [CrossRef] [PubMed]

47. De Souza, L.P.; Naake, T.; Tohge, T.; Fernie, A.R. From chromatogram to analyte to metabolite. How to pick horses for courses from the massive web resources for mass spectral plant metabolomics. GigaScience 2017, 6, 1-20. [CrossRef] [PubMed]

48. Mithöfer, A.; Boland, W. Do you speak chemistry. EMBO Rep. 2016, 17, 626-629. [CrossRef] [PubMed]

49. Mithöfer, A.; Boland, W. Plant defense against herbivores. Chemical aspects. Annu. Rev. Plant Biol. 2012, 63, 431-450. [CrossRef] [PubMed]

50. Kaplan, F.; Guy, C.L. $\beta$-Amylse induction and the protective role of maltose during temperature shock. Plant Physiol. 2004, 135, 1674-1684. [CrossRef] [PubMed]

51. Tenenboim, H.; Burgos, A.; Willmitzer, L.; Brotman, Y. Using lipidomics for expanding the knowledge on lipid metabolism in plants. Biochimie 2016, 130, 91-96. [CrossRef] [PubMed]

52. Frankel, E.N. Lipid Oxidation, 2nd ed.; Woodhead Publishing in Food Science, Technology and Nutrition: Philadelphia, PA, USA, 2012.

53. El-Hafid, L.; Pham, T.A.; Zuily-Fodil, Y.; Vieira da Silva, J. Enzymatic Breakdown of Polar Lipids in Cotton Leaves under Water Stress. 1. Degradation of Monogalactosyl-Diacylglycerol. Plant Physiology Biochemistry 1989. Available online: http://agris.fao.org/agris-search/search.do?recordID=FR9001726 (accessed on 29 June 2018).

54. Hubac, C.; Guerrier, D.; Ferran, J.; Tremolieres, A. Change of leaf lipid composition during water stress in two genotypes of lupinus albus resistant or susceptible to drought. Plant Physiol. Biochem. 1989, 27, 737-744.

55. Pham, T.A.T.; Vieira da Silva, J.; Mazliak, P. The role of membrane lipids in drought resistance of plants. Bulletin de la Société Botanique de France. Actual. Bot. 1990, 137, 99-114.

56. Quartacci, M.F.; Pinzino, C.; Sgherri, C.L.; Navari-Izzo, F. Lipid composition and protein dynamics in thylakoids of two wheat cultivars differently sensitive to drought. Plant Physiol. 1995, 108, 191-197. [CrossRef] [PubMed]

57. Kaoua, M.; Serraj, R.; Benichou, M.; Hsissou, D. Comparative sensitivity of two Moroccan wheat varieties to water stress: The relationship between fatty acids and proline accumulation. Bot. Stud. 2006, 47, 51-60. 
58. Moradi, P.; Mahdavi, A.; Khoshkam, M.; Iriti, M. Lipidomics unravels the role of leaf lipids in thyme plant response to drought stress. Int. J. Mol. Sci. 2017, 18, 2067. [CrossRef] [PubMed]

59. De Paula, F.M.; Thi, A.P.; de Silva, J.V.; Justin, A.; Demandre, C.; Mazliak, P. Effects of water stress on the molecular species composition of polar lipids from Vigna unguiculata L. Leaves. Plant Sci. 1990, 66, 185-193. [CrossRef]

60. Hamrouni, I.; Salah, H.B.; Marzouk, B. Effects of water-deficit on lipids of safflower aerial parts. Phytochemistry 2001, 58, 277-280. [CrossRef]

61. Li, Q.; Zheng, Q.; Shen, W.; Cram, D.; Fowler, D.B.; Wie, Y. Understanding the biochemical basis of temperature-induced lipid pathway adjustments in plants. Plant Cell 2015, 27, 86-103. [CrossRef] [PubMed]

62. Köhl, K. Metabolomics on Combined Abiotic Stress Effects in Crops. In Drought Stress Tolerance in Plants; Hossain, M., Wani, S., Bhattacharjee, S., Burritt, D., Tran, L.S., Eds.; Springer: Cham, Switzerland, 2016; Volume 2.

63. Nakabayashi, R.; Saito, K. Integrated metabolomics for abiotic stress responses in plants. Curr. Opin. Plant Boil. 2015, 24, 10-16. [CrossRef] [PubMed]

64. Okazaki, Y.; Saito, K. Integrated metabolomics and phytochemical genomics approaches for studies on rice. GigaScience 2016, 5, 1-7. [CrossRef] [PubMed]

65. Agrios, G. Genetics of plant disease. In Pant Pathology, 5th ed.; Elsvier Academic Press: Cambridge, MA, USA, 2005; pp. 125-174.

66. Aghnoum, R.; Marcel, T.C.; Johrde, A.; Pecchioni, N.; Schweizer, P.; Niks, R.E. Basal host resistance of barley to powdery mildew: Connecting quantitative trait loci and candidate genes. Mol. Plant Microbe Interact. 2010, 23, 91-102. [CrossRef] [PubMed]

67. Valdés-López, O.; Thibivilliers, S.; Qiu, J.; Xu, W.W.; Nguyen, T.H.; Libault, M.; Le, B.H.; Goldberg, R.B.; Hill, C.B.; Hartman, G.L.; et al. Identification of quantitative trait loci controlling gene expression during the innate immunity response of soybean. Plant Physiol. 2011, 157, 1975-1986. [CrossRef] [PubMed]

68. Massman, J.; Cooper, B.; Horsley, R.; Neat, S.; Dill-Macky, R.; Chao, S.; Dong, Y.; Schwarz, P.; Muehlbauer, G.J.; Smith, K.P. Genome-wide association mapping of Fusarium head blight resistance in contemporary barley breeding germplasm. Mol. Breed. 2011, 27, 439-454. [CrossRef]

69. Gunnaiah, R.; Kushalappa, A.C.; Duggavathi, R.; Fox, S.; Somers, D.J. Integrated metabolo-proteomic approach to decipher the mechanisms by which wheat QTL (Fhb1) contributes to resistance against Fusarium graminearum. PLoS ONE 2012, 7, e40695. [CrossRef] [PubMed]

70. Bollina, V.; Kumaraswamy, G.K.; Kushalappa, A.C.; Choo, T.M.; Dion, Y.; Rioux, S.; Faubert, D.; Hamzehzarghani, H. Mass spectrometry-based metabolomics application to identify quantitative resistance-related metabolites in barley against Fusarium head blight. Mol. Plant Pathol. 2010, 11, 769-782. [CrossRef] [PubMed]

71. Ballester, A.R.; Lafuente, M.T.; de Vos, R.C.; Bovy, A.G.; González-Candelas, L. Citrus phenylpropanoids and defence against pathogens. Part I: Metabolic profiling in elicited fruits. Food Chem. 2013, 136, 178-185. [CrossRef] [PubMed]

72. Machado, A.R.T.; Campos, V.A.C.; da Silva, W.J.R.; Campos, V.P.; de Mattos Zeri, A.C.; Olivera, D.F. Metabolic profiling in the roots of coffee plants exposed to the coffee root-knot nematode, Meloidogyne exigua. Eur. J. Plant Pathol. 2012, 134, 431-441. [CrossRef]

73. Sana, T.R.; Fischer, S.; Wohlgemuth, G.; Katrekar, A.; Jung, K.H.; Ronald, P.C.; Fiehn, O. Metabolomic and transcriptomic analysis of the rice response to the bacterial blight pathogen Xanthomonas oryzae pv. oryzae. Metabolomics 2010, 6, 451-465. [CrossRef] [PubMed]

74. Batovska, D.I.; Todorova, I.T.; Nedelcheva, D.V.; Parushev, S.P.; Atanassov, A.I.; Hvarleva, T.D.; Djakova, G.J.; Bankova, V.S.; Popov, S.S. Preliminary study on biomarkers for the fungal resistance in Vitis vinifera leaves. J. Plant Physiol. 2008, 165, 791-795. [CrossRef] [PubMed]

75. Suh, M.C.; Samuels, A.L.; Jetter, R.; Kunst, L.; Pollard, M.; Ohlrogge, J. Cuticular lipid composition, surface structure, and gene expression in Arabidopsis stem epidermis. Plant Physiol. 2005, 139, 1649-1665. [CrossRef] [PubMed]

76. Keymer, A.; Pimprikar, P.; Wewer, V.; Huber, C.; Brands, M.; Bucerius, S.L.; Delaux, P.M.; Klingl, V.; Röpenack-Lahaye, E.V.; Wang, T.L.; et al. Lipid transfer from plants to arbuscular mycorrhiza fungi. Elife 2017, 6, e29107. [CrossRef] [PubMed] 
77. Cellini, F.; Chesson, A.; Colquhoun, I.; Constable, A.; Davies, H.V.; Engel, K.H.; Gatehouse, A.M.R.; Kärenlami, S.; Kok, E.J.; Leguay, J.-J.; et al. Unintended effects and their detection in genetically modified crops. Food Chem. Toxicol. 2004, 24, 1089-1125. [CrossRef] [PubMed]

78. Pinu, F.R. Metabolomics-The new frontier in food safety and quality research. Food Res. Int. 2015, 72, 80-81. [CrossRef]

79. Shephard, G.S. Current status of mycotoxin analysis: A critical review. J. AOAC Int. 2016, 99, 842-848. [CrossRef] [PubMed]

80. Taiz, L.; Zeiger, E. Plant Physiology, 5th ed.; Sinauer Associates: Sunderland, MA, USA, 2010.

81. Novák, O.; Napier, R.; Ljung, K. Zooming in on plant hormone analysis: Tissue- and cell-specific approaches. Annu. Rev. Plant Biol. 2017, 68, 323-348. [CrossRef] [PubMed]

82. Davies, P.J. Plant Hormones: Biosynthesis, Signal Transduction, Action! 3rd ed.; Kluwer Academic Publishers: Dordrecht, The Netherlands, 2010.

83. Peleg, Z.; Blumwald, E. Hormone balance and abiotic stress tolerance in crop plants. Curr. Opin. Plant Biol. 2011, 14, 290-295. [CrossRef] [PubMed]

84. Santner, A.; Estelle, M. The ubiquitin—Proteasome system regulates plant hormone signaling. Plant J. 2010, 61, 1029-1040. [CrossRef] [PubMed]

85. Porfírio, S.; Gomes da Silva, M.D.R.; Peixe, A.; Cabrita, M.J.; Azadi, P. Current analytical methods for plant auxin quantification-A review. Anal. Chim. Acta 2016, 902, 8-21. [CrossRef] [PubMed]

86. Šimura, J.; Antoniadi, I.; Široká, J.; Tarkowska, D.; Strnad, M.; Ljung, K.; Novak, O. Plant hormonomics: Multiple phytohormone profiling by targeted metabolomics. Plant Physiol. 2018. [CrossRef] [PubMed]

87. Rhy, H.; Cho, Y. Plant hormons in salt stress tolerance. J. Plant Biol. 2015, 58, 147-155.

88. Ramos, L. Critical overview of selected contemporary sample preparation techniques. J. Chromatogr. A 2012, 1221, 84-98. [CrossRef] [PubMed]

89. Prinsen, E.; Van Dongen, W.; Esmans, E.L.; Van Onckelen, H.A. HPLC linked electrospray tandem mass spectrometry: A rapid and reliable method to analyse indole-3-acetic acid metabolism in bacteria. J. Mass Spectrom. 1997, 32, 12-22. [CrossRef]

90. Waterval, J.; Lingeman, H.; Bult, A.; Underberg, W.J. Derivatization trends in capillary electrophoresis. Electrophoresis 2000, 21, 4029-4045. [CrossRef]

91. Egging, M.; Wijtmans, M.; Ekkebus, R.; Lingeman, H.; de Esch, I.J.; Kool, J.; Niessen, W.M.A.; Irth, H. Development of a selective ESI-MS derivatization reagent: Synthesis and optimization for the analysis of aldehydes in biological mixtures. Anal. Chem. 2008, 80, 9042-9051. [CrossRef] [PubMed]

92. International Food Information Council Foundation, Washington, D.C. 2016 Food and Health Survey. Available online: http:/ / www.foodinsight.org/articles/2016-food-and-health-survey-food-decision-2016impact-growing-national-food-dialogue (accessed on 3 December 2016).

93. Dunkel, A.; Steinhaus, M.; Kotthoff, M.; Nowak, B.; Krautwurst, D.; Schieberle, P.; Hofmann, T. Nature's chemical signatures in human olfaction: A foodborne perspective for future biotechnology. Angew. Chem. Int. Ed. Engl. 2014, 53, 7124-7143. [CrossRef] [PubMed]

94. Schieberle, P.; Hofmann, T. Mapping the combinatorial code of food flavors by means of molecular sensory science approach. In Food Flavors_Chemical, Sensory and Technological Properties; Jelen, H., Ed.; CRC Press: Boca Raton, FL, USA, 2012; pp. 411-437.

95. Li, J.-X.; Schieberle, P.; Steinhaus, M. Insights into the key compounds of durian (Durio zibethinus L. 'Monthong') pulp odor by odorant quantitation and aroma simulation experiments. J. Agric. Food Chem. 2016, 65, 639-647. [CrossRef] [PubMed]

96. Munafo, J.P.; Didzbalis, J.; Schnell, R.J.; Steinhaus, M. Insights into the key aroma compounds in mango (Mangifera indica L. 'Haden') fruits by stable isotope dilution quantitation and aroma simulation experiments. J. Agric. Food Chem. 2016, 64, 4312-4318. [CrossRef] [PubMed]

97. Czepa, A.; Hofmann, T. Quantitative studies and sensory analyses on the influence of cultivar, spatial tissue distribution, and industrial processing on the bitter Off-taste of carrots (Daucus carota L.) and carrot products. J. Agric. Food Chem. 2004, 52, 4508-4514. [CrossRef] [PubMed]

98. Schmiech, L.; Uemra, D.; Hofmann, T. Reinvestigation of the bitter compounds in carrots (Daucus carota L.) by using a molecular sensory science approach. J. Agric. Food Chem. 2008, 56, 10252-10260. [CrossRef] [PubMed] 
99. Stark, T.; Hofmann, T. Isolation, structure determination, synthesis, and sensory activity of $\mathrm{N}$-phenylpropenoyl-L-amino acids from cocoa (Theobroma cacao). J. Agric. Food Chem. 2005, 53, 5419-5428. [CrossRef] [PubMed]

100. Dawid, C.; Hofmann, T. Structural and sensory characterization of bitter tasting steroidal saponins from asparagus spears (Asparagus officinalis L.). J. Agric. Food Chem. 2012, 60, 11889-11900. [CrossRef] [PubMed]

101. Dawid, C.; Hofmann, T. Identification of sensory-active phytochemicals in asparagus (Asparagus officinalis L.). J. Agric. Food Chem. 2012, 60, 11877-11888. [CrossRef] [PubMed]

102. Dawid, C.; Hofmann, T. Quantitation and bitter taste contribution of saponins in fresh and cooked white asparagus (Asparagus officinalis L.). Food Chem. 2013, 145, 427-436. [CrossRef] [PubMed]

103. Dawid, C.; Henze, A.; Frank, O.; Glabasnia, A.; Rupp, M.; Buening, K.; Orlikowski, D.; Bader, M.; Hofmann, T. Structural and sensory characterization of key pungent and tingling compounds from black pepper (Piper nigrum L.). J. Agric. Food Chem. 2012, 60, 2884-2895. [CrossRef] [PubMed]

104. Schwarz, B.; Hofmann, T. Sensory-Guided Decomposition of Red Current Juice (Ribes rubrum) and Structure Determination of Key Astringent Compounds. J. Agric. Food Chem. 2007, 55, 1394-1404. [CrossRef] [PubMed]

105. Scharbert, S.; Holzmann, N.; Hofmann, T. Identification of the astringent taste compounds in black tea infusions by combining instrumental analysis and human bioresponse. J. Agric. Food Chem. 2004, 52, 3498-3508. [CrossRef] [PubMed]

106. Hellfritsch, C.; Brockhoff, A.; Stähler, F.; Meyerhof, W.; Hofmann, T. Human psychometric and taste receptor responses to steviol glycosides. J. Agric. Food Chem. 2012, 60, 6782-6793. [CrossRef] [PubMed]

107. Brock, A.; Hofmann, T. Identificatioion of the Key Astringent Compounds in Spinach (Spinacia oleracea) by Means of the Taste Dilution Analysis. Chem. Percept. 2008, 1, 268-281. [CrossRef]

108. Hofmann, T.; Krautwurst, D.; Schieberle, P. Current status and future perspectives in flavor research: Highlights of the 11th Wartburg Symposium on flavor chemistry \& biology. J. Agric. Food Chem. 2018, 66, 2197-2203. [PubMed]

109. Harding, V.K.; Heale, J.B. The accumulation of inhibitory compounds in the induced resistance response of carrot root slices to Botrytis cinerea. Physiol. Plant Pathol. 1981, 18, 7-15. [CrossRef]

110. Lund, E.D.; White, J.M. Polyacetylenes in Normal and waterstressed 'Orlando Gold' carrots (Daucus carota). J. Sci. Food Agric. 1990, 51, 507-516. [CrossRef]

111. Olsson, K.; Svensson, R. The influence of polyacetylenes on the susceptibility of carrots to storage diseases. J. Phytopathol. Phytopathol. Z. 1996, 144, 441-447. [CrossRef]

112. Kreutzmann, S.; Christensen, L.P.; Edelenbos, M. Investigation of bitterness in carrots (Daucus carota L.) based on quantitative chemical and sensory analyses. LWT Food Sci. Technol. 2008, 41, 193-205. [CrossRef]

113. Kreutzmann, S.; Svensson, V.T.; Thybo, A.K.; Bro, R.; Petersen, M.A. Prediction of sensory quality in raw carrots (Daucus carota L.) using multi-block LS-ParPLS. Food Qual. Preference 2008, 19, 609-617. [CrossRef]

114. Kidmose, U.; Hansen, S.L.; Christensen, L.P.; Edelenbos, M.; Larsen, E.; Nørbæk, R. Effects of genotype, root size, storage, and processing on bioactive compounds in organically grown carrots (Daucus carota L.). J. Food Sci. 2004, 69, S388-S394. [CrossRef]

115. Lund, E.D.; Bruemmer, J.H. Acetylenic compounds in stored packaged carrots. J. Sci. Food Agric. 1991, 54, 287-294. [CrossRef]

116. Singldinger, B.; Dunkel, A.; Bahmann, D.; Bahmann, C.; Kadow, D.; Bisping, B.; Hofmann, T. New taste-active 3-(O- $\beta$-D-glucosyl)-2-oxoindole-3-acetic acids and diarylheptanoids in Cimiciato-infected hazelnuts. J. Agric. Food Chem. 2018, 66, 4660-4673. [CrossRef] [PubMed]

117. Mei, X.; Liu, X.; Zhou, Y.; Wang, X.; Zeng, L.; Fu, X.; Li, J.; Tang, J.; Dong, F.; Yang, Z. Formation and emission of linalool in tea (Camellia sinensis) leaves infested by tea green leafhopper (Empoasca (Matsumurasca) onukii Matsuda). Food Chem. 2017, 237, 356-363. [CrossRef] [PubMed]

118. Zhou, Y.; Zeng, L.; Liu, X.; Gui, J.; Mei, X.; Fu, X.; Dong, F.; Tang, J.; Zhang, L.; Yang, Z. Formation of $(E)$-nerolidol in tea (Camellia sinensis) leaves exposed to multiple stresses during tea manufacturing. Food Chem. 2017, 231, 78-86. [CrossRef] [PubMed]

(C) 2018 by the authors. Licensee MDPI, Basel, Switzerland. This article is an open access article distributed under the terms and conditions of the Creative Commons Attribution (CC BY) license (http:/ / creativecommons.org/licenses/by/4.0/). 